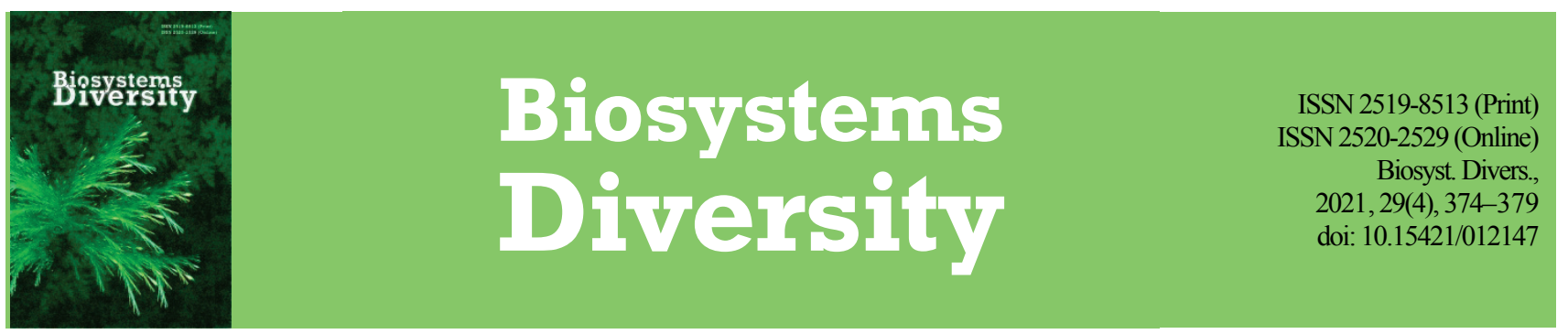

\title{
Seasonal dynamics of Diptera in individual biotopes in the center of the European part of Russia
}

\author{
A. B. Ruchin, M. N. Esin \\ Joint Directorate of the Mordovia State Nature Reserve and National Park “Smolny”, Saransk, Russia
}

Article info

Received 01.10.2021

Received in revised form 25.10.2021

Accepted 27.10.2021

Joint Directorate

of the Mordovia State Nature

Reserve and National Park

"Smolny", Krasnava st., 30

Saransk, 430005, Republic

of Mordovia, Russia.

Tel.: +78-344-52-96-48.

E-mail:ruchin.alexander@

gmail.com

\section{Ruchin, A. B., \& Esin, M. N. (2021). Seasonal dynamics of Diptera in individual biotopes in the center of the European part of Russia. Biosystems Diversity, 29(4), 374-379. doi:10.15421/012147}

In a changing climate, phenological observations are gaining new importance. They can tell what changes are taking place in certain environmental conditions. The studies were conducted in 2019 within the territory of the Republic of Mordovia (the center of the European part of Russia). Beer traps (beer as a bait) were used to collect Diptera. The material was collected in the period from April to October in different forest biotopes (pine forest, lime forest, aspen forest, birch forest and oak forest) and the air temperature was recorded at the same time. In total, more than 14.000 specimens of Diptera were recorded. Overall, 29 families were recorded. The largest number of families was observed for birch (23 families) and pine (24 families) forests, the smallest number - in aspen forest (16 families). The families Muscidae, Drosophilidae, Calliphoridae had the largest number of captured individuals $(44.5 \%, 35.2 \%, 7.6 \%$ of the total number of individuals respectively). The highest number of individuals was captured in oak forest. The dynamics of abundance in all biotopes were similar and were characterized by the same number of declines and rises. The first small significant peak in the number of Diptera occurred in the first half of summer. A slight increase in the number of specimeni occurred in mid-June. In the second half of September, there was a gradual increase in the number and the maximum peak was recorded in mid-October, then there was a decline. The autumn increase in the number of Diptera in all five biotopes exceeded the summer peak by several times. This dynamic was typical for most families. However, species from the family Lonchaeidae had the peak in July. For our better understanding of the changes in the seasonal dynamics of the number of Diptera, long-term observations in different climatic zones are needed.

Keywords: insects; number; phenological changes; Republic of Mordovia; Mordovia State Nature Reserve.

\section{Introduction}

Phenological changes are the key feature in temperate zones and they determine the activity cycles of animals and plants (Schwartz, 2003; Harvey et al., 2020; Marshall et al., 2020; Minin et al., 2020). In response to the seasonal natural changes, the species composition of populations and the number of species significantly fluctuates (Wieher et al., 2011; Altermatt, 2012; Blackshaw \& Esbjerg, 2017; Chick et al., 2019; Barkalov \& Khruleva, 2021; Polevoi, 2021). Seasonal phenology is often caused by abiotic environmental factors, including environmental stressors. Together they can have a clear impact on the composition of the community (McGill et al., 2006; Hallett et al., 2018; Höök et al., 2020).

Different groups of insects had very clear seasonal rhythms, in particular Coleoptera, Lepidoptera, Hymenoptera and others (Roy et al., 2000; Kuussaari et al., 2007; Ulyshen et al., 2011; Handley et al., 2015; Brooks et al., 2017; Ruchin et al., 2018, 2021; Stojko \& Senkevich, 2018; Krivosheina \& Krivosheina, 2019; Ruchin, 2021). Seasonal dynamics of individual families and species of Diptera are also interesting to study. For example, in Mexico, the main peaks in the number of Tephritidae were recorded from February to October, and they coincided with the phenological stages of fruiting, ripening and fruit harvesting (Rodríguez-Rodríguez et al., 2018). In Brazil, Drosophila willistoni was more numerous in autumn, while the $D$. cardini and D. tripunctata were numerous in winter and spring respectively, and D. repleta was active in both seasons (Bizzo et al., 2010). The peak number of $D$. nebulosa occurred in December (Torres \& Madi-Ravazzi, 2006). The seasonal activity of Syrphidae was studied in the Komi Republic.

Based on the analysis of the activity of 194 species, ten phenological groups were identified. They had different peaks of activity during the season. Epy Tumber of active adult predators decreased early July. At that time, the appearance of early summer species ended, and late summer species remained in the larval stage. The peak activity of detritophages was observed in mid-July. Hygrophile and mesophile dipterans were active in mid-May (Pestov, 2010).

The annual temporal pattern in the relative abundance of Culicidae closely correlated with dynamics of water level in the Drava and Danube rivers, especially in 1999 and 2004 (Bogojevic et al., 2009). The peak population of Aedes albopictus in Portugal was observed from September to November (Osório et al., 2020). The seasonal activity of 10 Tabanidae species was studied in Turkey. Abundance of Dasyrhamphis umbrinus, Tabanus bifarius, T. quatuornotatus and T. unifasciatus peaked in June, and other species peaked in July. The species Haematopota subcylindrica and Tabanus bromius had the longest flight period from the first week of May to the middle of September (Altunsoy \& Kiliç, 2012). In Bulgaria, Tabanidae were active from the second half of May to the mid-September. The peak of seasonal abundance was observed in the first half of July. Tabanus quatuornotatus, T. tergestinus and Philipomyia graeca were the most widespread species (Ganeva \& Kalmushka, 2019). In the territory of Eastern Croatia in 1992-1998, the seasonal activity was analyzed for 25 species of Tabanidae. The peak number was determined for two species in May, for six species in June, for 10 species in July, for five species in August and for one species in September. Only Tabanus autumnalis showed two peaks of abundance - the first in May and the second in July. All other species had only one peak in abundance during the study period (Krčmar, 1999).

\section{Materials and methods}

The studies were conducted from April to October in 2019 (Republic of Mordovia, Temnikovsky district, territory of Mordovia State Nature Reserve). The Mordovia State Nature Reserve is located on the right bank of the Moksha River, its area accounts for $321.62 \mathrm{~km}^{2}$. The territory of the Mordovia State Nature Reserve is included in the zone of coniferous-deciduous forests on the border with the forest-steppe. Forest communities 
occupy $89.3 \%$ of the entire territory. Pine (Pinus sylvestris L.) is the main forest-forming species. Birch (Betula pendula Roth) and birch forests occupy the second largest forest area in the Mordovia State Nature Reserve. These are mainly secondary communities on the sites of cuttings and burnt pine forests. Oak forests occupy a relatively small area. They are common in the floodplain of the Moksha River in the western part. Spruce forests (from Picea abies L.) and alders (from Alnus glutinosa (L.) Gaertn.) are located mainly in floodplains of rivers and streams and occupy small areas (Ruchin \& Egorov, 2017; Ruchin \& Mikhailenko, 2018).

In order to study the seasonal dynamics, traps were placed in five different biotopes (a more detailed description of the biotopes is given in the publication by Ruchin et al. (2021). The names of biotopes are given according to the predominant tree species in them: 1 - the forest area with predominance of Pinus sylvestris (pine forest); 2 - the forest area with predominance of Tilia cordata (lime forest); 3 - the forest area with predominance of Populus tremula (aspen forest); 4 - the forest area with predominance of Betula pendula (birch forest); 5 - the forest area with predominance of Quercus robur (oak forest).

All collections were carried out by traps that we designed ourselves. As a trap, we used a five-liter plastic container with a window cut out on one side at the distance of $10 \mathrm{~cm}$ from the bottom (Ruchin et al., 2020). Beer was the bait. Sugar was added for fermentation. In each biotope, two traps were installed under the forest canopy at the distance of five meters from each other. Traps were hung on tree trunks in the crown at the height of seven to eight meters. The sampling period ranged four to 17 days. At the same time, the air temperature was measured daily during the day and night (maximum and minimum parameters). During the experiment, more than 14,000 Diptera individuals were captured and viewed. When analyzing the results, we used only data on the quantitative parameter (number) of all individuals of some Diptera families in traps for the exposure time. The exposure time was the period between hanging a trap and taking samples for the analysis (expressed in days). Unidentified individuals were not used in the calculations, which could not be accurately attributed to a particular family.

\section{Results}

During the growing season, in total, 29 species from the Diptera family were captured in beer traps in five biotopes. The largest number of families was obtained in birch (23 families) and pine (24 families) forests, the smallest number was in aspen forest (16 families, Fig. 1). In all biotopes, there were species from 16 families: Muscidae, Aulacigastridae, Pallopteridae, Phoridae, Anthomyiidae, Syrphidae, Fanniidae, Lonchaeidae, Anisopodidae, Scathophagidae, Lauxaniidae, Dryomyzidae, Calliphoridae, Heleomyzidae, Drosophilidae, Ulidiidae.

Representatives of 10 families (Hybotidae, Tachinidae, Tabanidae, Polleniidae, Scenopinidae, Sciomyzidae, Simuliidae, Piophilidae, Odiniidae, Rhagionidae) were found only once in one biotope. Apparently, species from these families randomly fell into beer traps. The families Muscidae, Drosophilidae, Calliphoridae had the largest number of captured individuals (44.5\%, 35.2\%, 7.6\% of the total number of individuals respectively). In the forests of central Russia, the seasonal activity of Muscidae was two-vertex. The biggest autumn peak was recorded in the first half of October (Fig. 2). Drosophilidae and Calliphoridae were characterized by peak in the populations, which began at the end of September and was the highest in mid-October (Fig. 3, 4). The maximum number of Anisopodidae was observed in all biotopes in October (Fig. 5). The largest number of Lonchaeidae species in all biotopes was seen in July (Fig. 6).

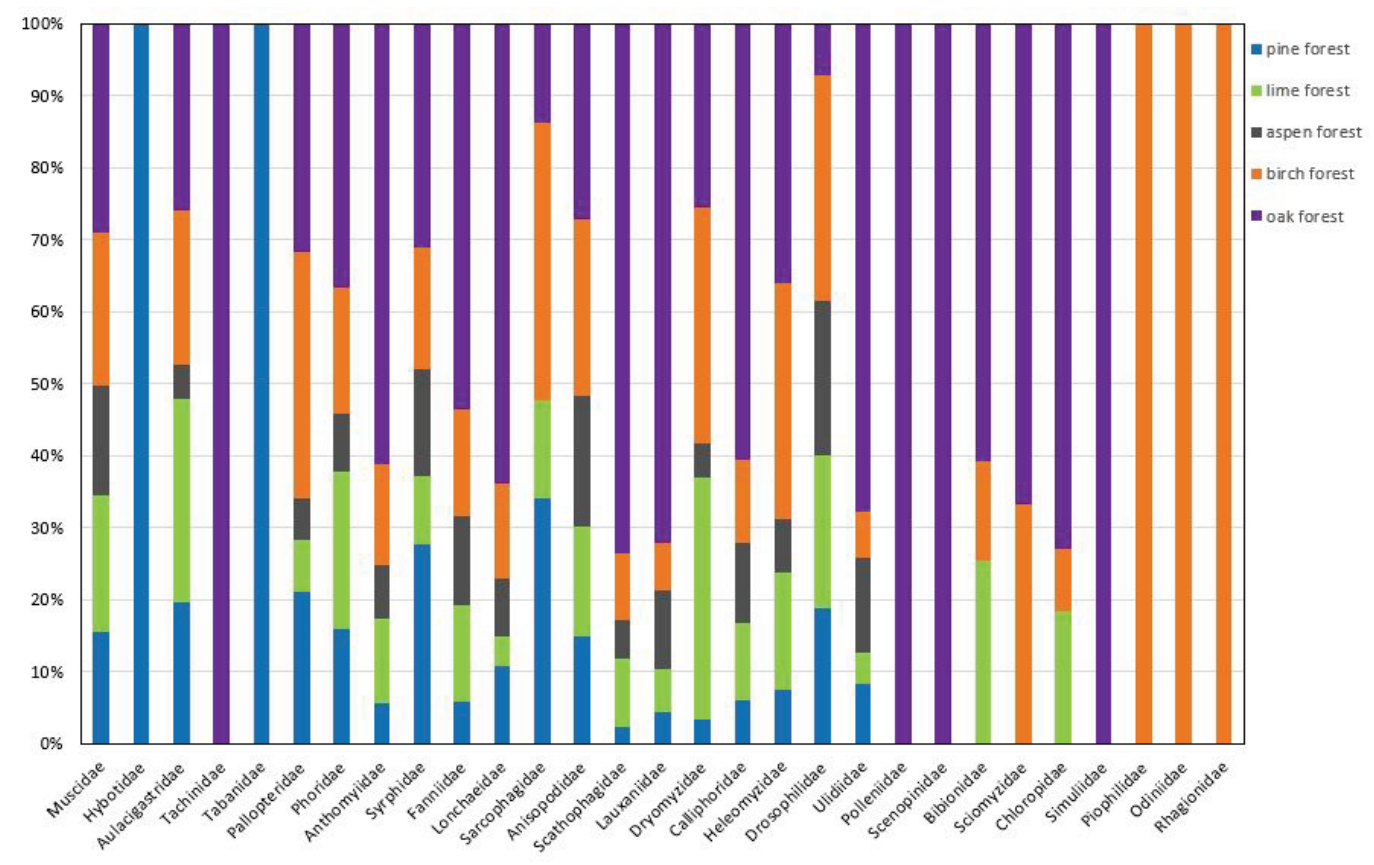

Fig. 1. The ratio of the number of individuals from Diptera families in different biotopes for the entire study season

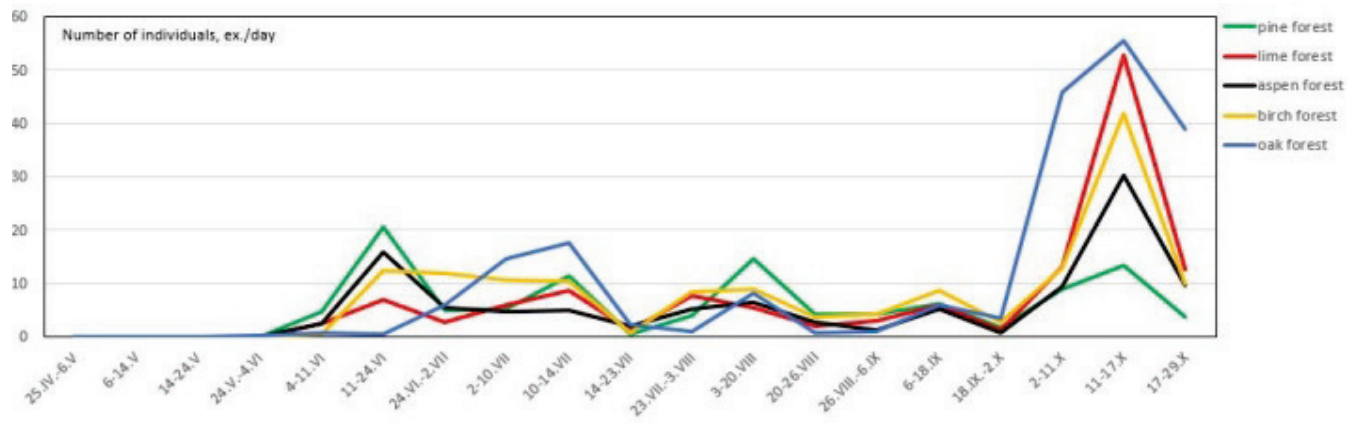

Fig. 2. Dynamics of the number of Muscidae individuals in different forest biotopes in the 2019 season in the center of European Russia 


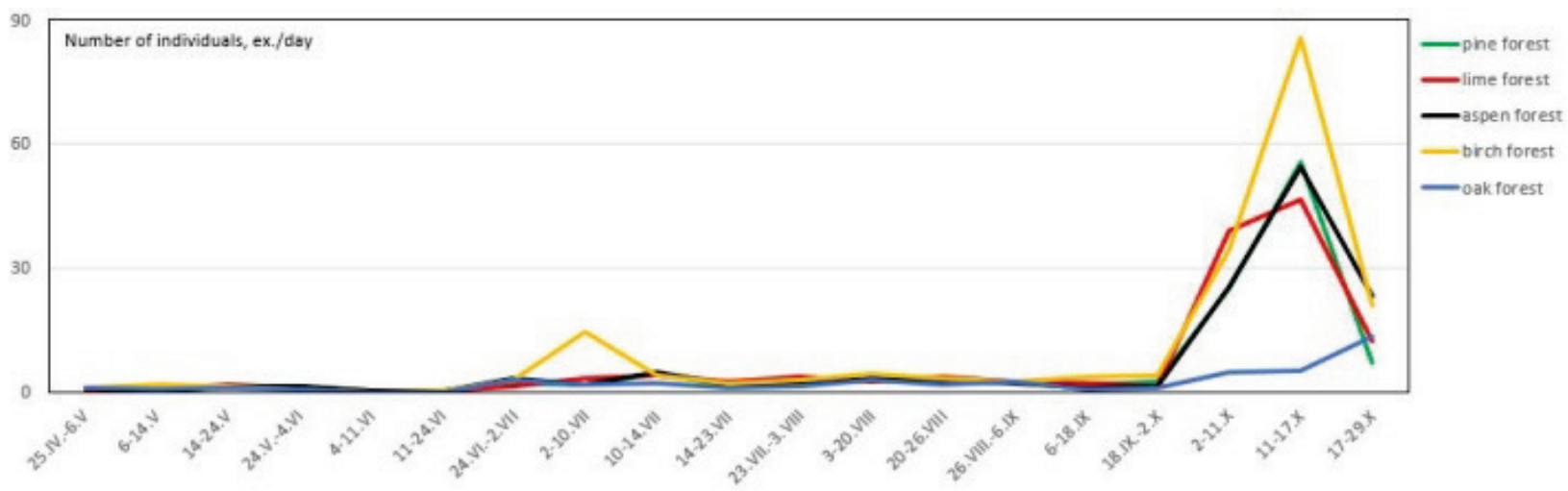

Fig. 3. Dynamics of the number of Drosophilidae individuals in different forest biotopes in the 2019 season in the center of European Russia

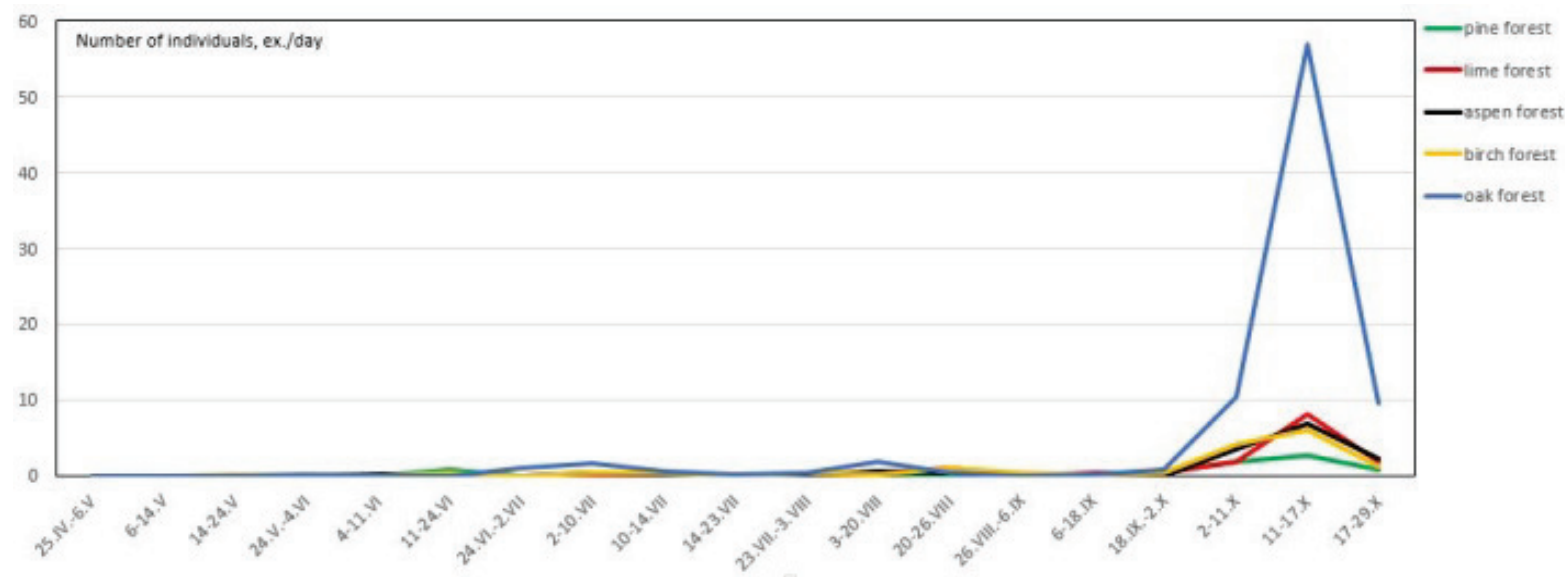

Fig. 4. Dynamics of the number of Calliphoridae individuals in different forest biotopes in the 2019 season in the center of European Russia

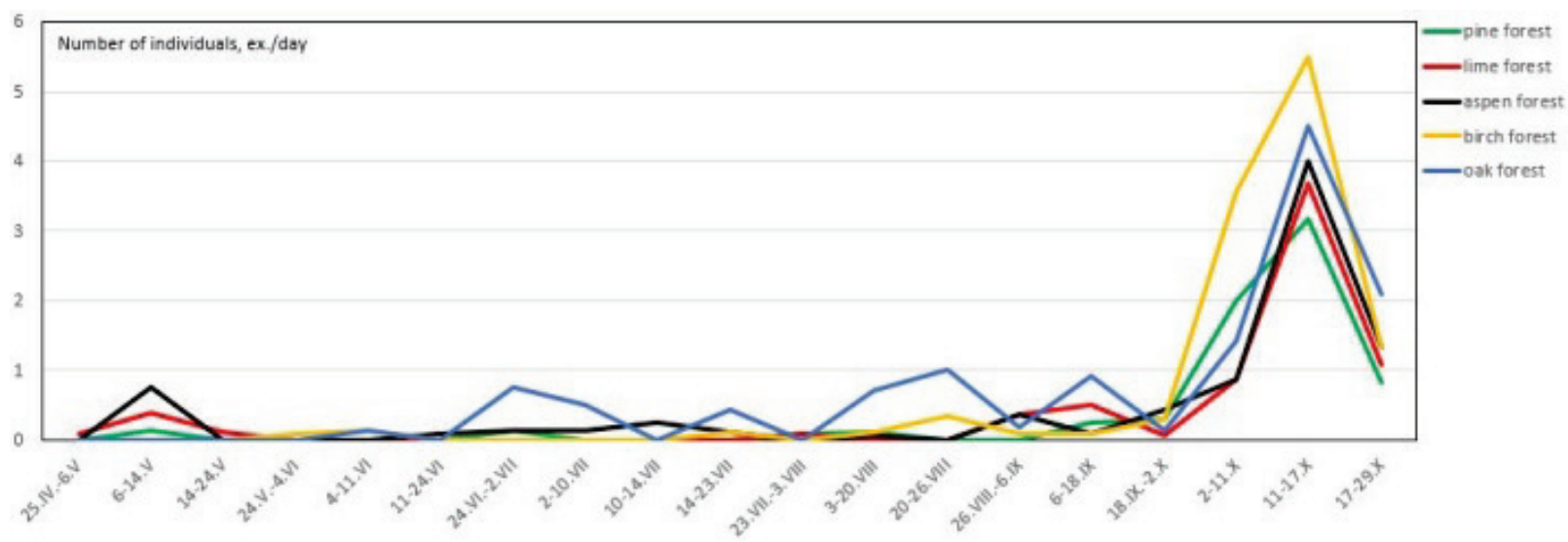

Fig. 5. Dynamics of the number of Anisopodidae individuals in different forest biotopes in the 2019 season in the center of European Russia

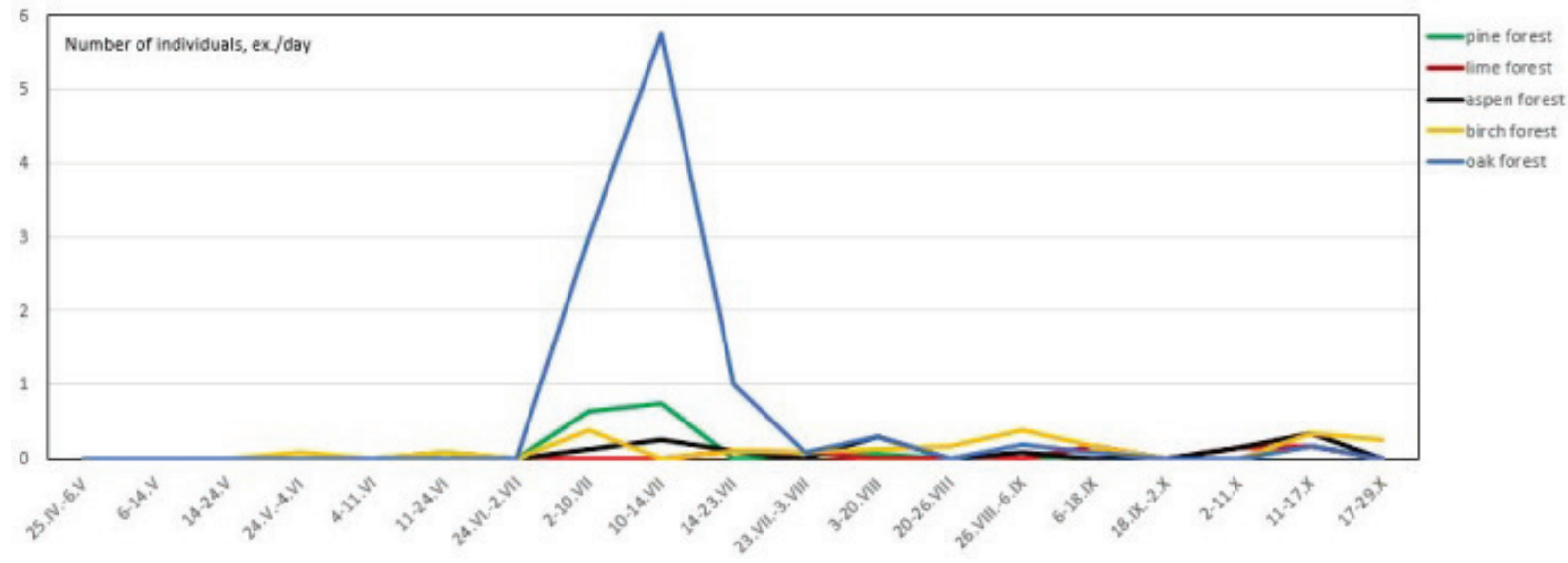

Fig. 6. Dynamics of the number of Lonchaeidae individuals in different forest biotopes in the 2019 season in the center of European Russia 


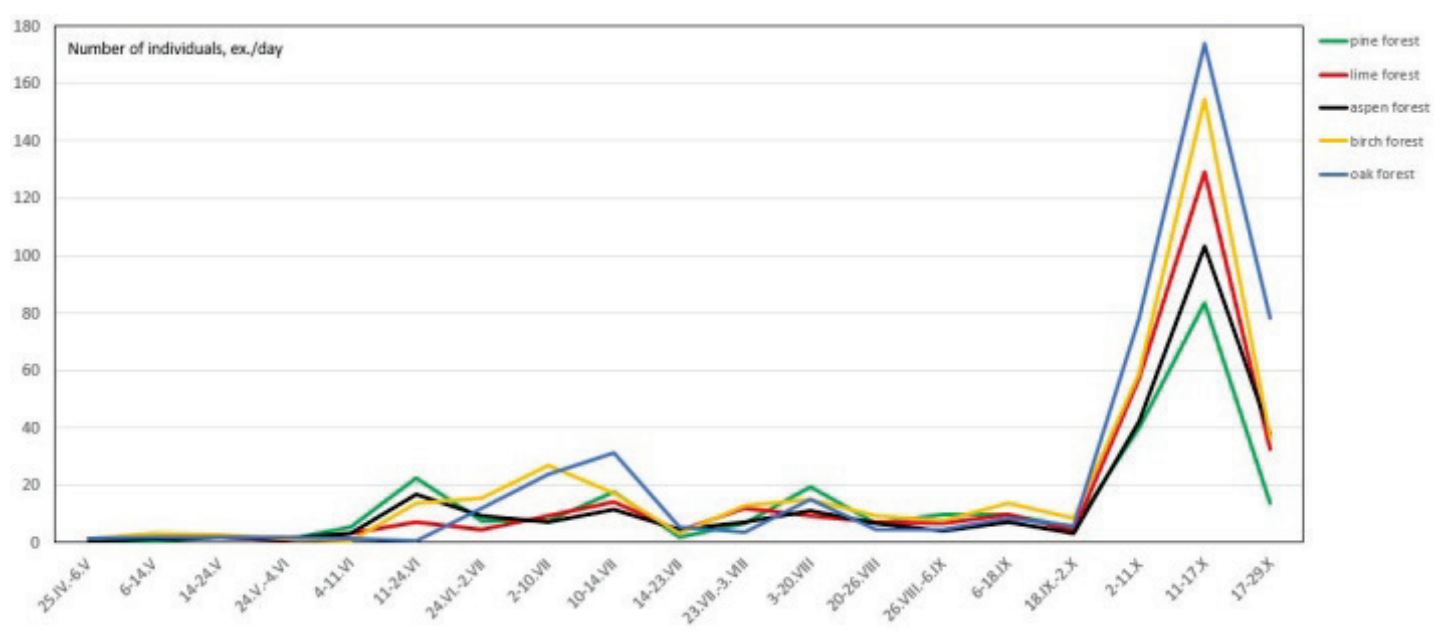

Fig. 7. Dynamics of the number of Diptera individuals in different forest biotopes in the 2019 season in the center of European Russia

The seasonal dynamics of the number of Diptera was expressed quite well and was logically. It should be noted that the population dynamics were almost similar in all biotopes. In late April, the number of this group was very low. Then there was a gradual increase in their number in the traps (Fig. 8). Based on the generalization of all the data obtained, the maximum number of Diptera was in the autumn months in all biotopes.
In the second half of September, there was a gradual increase in the number and the peak was recorded in mid-October, then there was a decline. Monitoring of the course of temperatures showed that there was a relationship with the peaks of the number of Diptera. However, it was more pronounced in the summer months, whereas in autumn, at low temperatures, the number in traps reached its maximum.

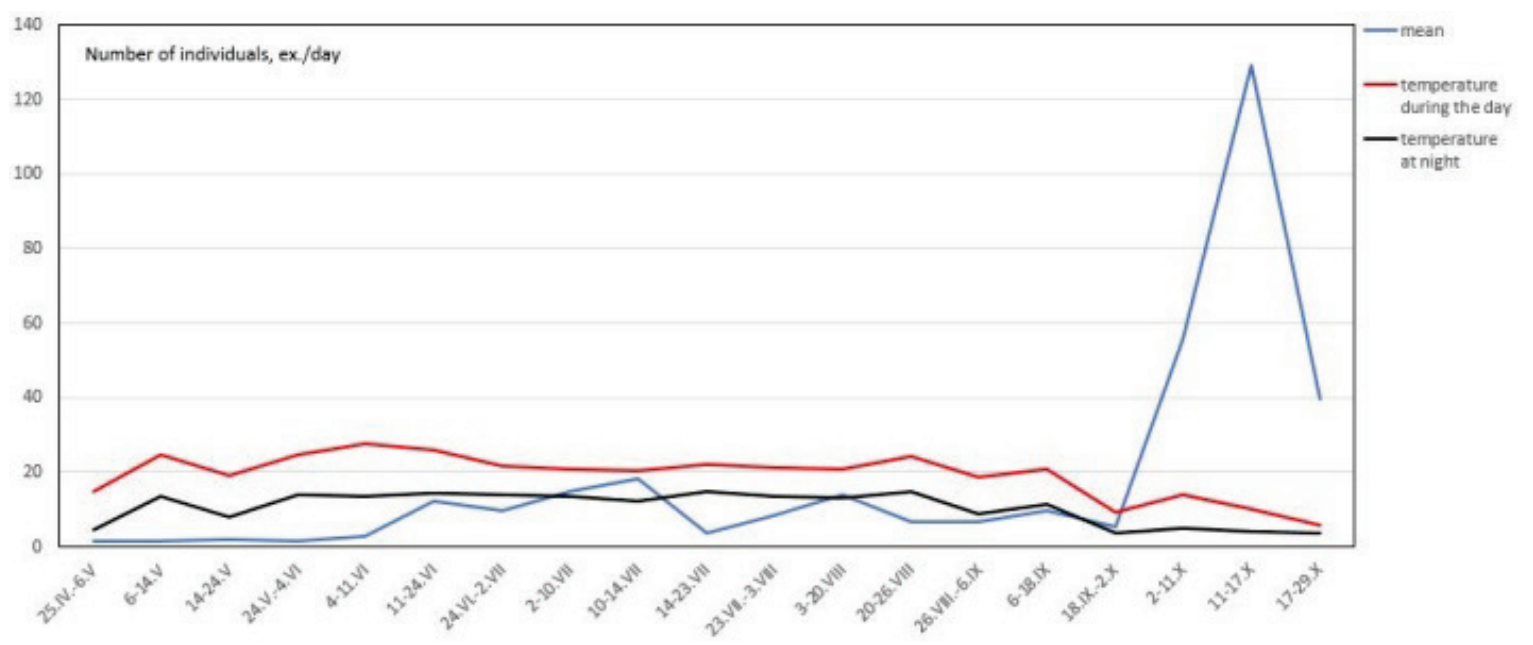

Fig. 8. Dynamics of the number of all Diptera families in comparison with temperature dynamics (the average of the number of individuals from all biotopes)

\section{Discussion}

As with most other insects, seasonal Diptera abundance cycles are associated with seasonal changes in temperature, day length, humidity, and other factors. Water levels and humidity regime have an effect on the seasonal activity of species breeding in water (Denlinger, 1980; Bogojevic et al., 2009; Nekrasova et al., 2016; Osório et al., 2020). Many parasitic dipterans depend on the seasonal activity of their hosts, which serve for the development of larvae (Shapiro, 1995; Paur \& Gray, 2011). In the tropics, seasonality often depends on the alternation of rainy and dry seasons (Mullens \& Peterson 2005; Godwin et al., 2017; Sevidzem \& ZingaKoumba, 2019). In a temperate climate, temperature and precipitation have the main impact on the seasonal cycles (Lysyk, 1993; Szyniszewska \& Tatem, 2014; Semelbauer et al., 2018).

The seasonal activity of Muscidae has a bimodal structure in warmer regions (Taylor et al., 2007), while the unimodal model is typical for the tropics and northern countries (Lysyk, 1993; Sinshaw et al., 2006; Uribe et al., 2010). Unimodal seasonal activity in the tropics is associated with the alternation of dry and rainy seasons, while in colder climates it is regulated by the alternation of cold and warm seasons. In the Mediterranean or semi-arid climate with dry summers and rainy winters, a stable fly population usually has a bimodal pattern with peaks in spring and autumn (Se- melbauer et al., 2018). In the conditions of central Russia, the seasonal activity of Muscidae was cyclical. There were two main peaks. The largest autumn peak occurred in the first half of October. The smaller peak took place in the second half of June. However, we observed two more small increases in the number of this family in traps: in the second half of July and at the end of August. It is possible that the June peak was associated with increase in the temperature and the activity of flies flying into traps. Other intermediate peaks are difficult to associate with the temperature factor. The largest peak in numbers is typical for the end of September and October. It is possible that the species of this family are actively preparing for wintering and show high activity in moderately high temperatures. In Slovakia, when studying the seasonal activity of Stomoxys calcitrans (Muscidae), two peaks were detected: a large peak was in summer, and a smaller peak in autumn (Semelbauer et al., 2018).

The impact of seasonal changes on the number of Drosophilidae was studied mainly in tropical and temperate climatic zones. Precipitation has the effect on their abundance in tropical regions while temperature fluctuations affect it in regions with a temperate climate (Torres \& Madi-Ravazzi, 2006; Poppe et al., 2013; Prigent et al., 2013; da Mata et al., 2015; Coutinho-Silva et al., 2017). Our studies have shown that Drosophilidae in the conditions of central Russia have one peak in abundance, which begins at the end of September with a maximum in mid-October. Daily tempera- 
tures were recorded at the level not higher than $15^{\circ} \mathrm{C}$, and at night - no more than $10^{\circ} \mathrm{C}$. At the same time, throughout the season, the number of this family in traps was more or less constant, without sharp increases or decreases. A similar dynamic was recorded in the experiments in Uşak province, Turkey (Zengin, 2020). The numbers of Drosophilidae were the highest in the temperature of $5-10{ }^{\circ} \mathrm{C}$, the average temperature for October and November. In September, when the temperature was more favourable for drosophilids, the amount of catch was lower (Zengin, 2020).

It is interesting that even during the peak period, the number of Drosophilidae in other biotopes in oak forest remained at a low level. It is possible that microclimatic conditions, for example, humidity, stratification, dense tree crowns, the predominant tree species, etc., have a certain influence on this biotope. For example, it was shown that the number of fruit flies was higher in cool-temperature forest (Tanabe et al., 2001).

Like other Diptera, many Calliphoridae species also have seasonal activity dynamics (Phillips et al., 2004; Dufek et al., 2019; Mali \& Zambare, 2019; Makaida et al., 2021). In our experiments, in contrast to drosophilids, the family Calliphoridae was found in oak forest in higher numbers. The activity peaked in October. This seasonal dependence was typical for all biotopes. The seasonal dynamics of species of the Anisopodidae family was similar in all biotopes. The maximum number was recorded in October. However, small differences in the number were also observed during other months. The activity especially peaked in the oak forest. It is possible that this was due to the departure of imagoes of individual species and, as a result, their number decreased in the traps.

This activity of Anisopodidae was partially confirmed by our previous collections from the territory of the Mordovia State Nature Reserve, where the maximum amount of the material was collected at the end of August and autumn (Dvoř́k et al., 2020). The life cycle of many species of Lonchaeidae is connected with their nutrition and reproduction. This relationship determines their seasonal dynamics (Johnsey et al., 1965; Souza-Filho et al., 2009; Carrero et al., 2013; Abbes et al., 2021). In our studies, the maximum activity of Lonchaeidae species was observed in all biotopes in July (MacGowan et al., 2021). However, the largest number was seen in the oak forest. In other biotopes, the number also increased in July, but not as noticeably as in oak forest.

As we mentioned above, the first small significant peak in the number of dipterans in our studies occurred in the first half of summer. Slight increase in the number of specimens occurred in mid-June.

In the first half of summer, increase in the number of Diptera was also observed. However, it was almost three times lower than the autumn peak. Apparently, it was associated with the appearance of the imago of the first species from different families. It was recorded after increase in daytime temperatures. Then, there was a slight decline amid a decrease in the temperature, but then again there was an increase in the number of Diptera in the traps. Usually, many imago species from various Diptera families hatch after the temperatures increases in the summer months (Kinjo et al., 2014; Chen et al., 2019). The second largest peak in the number was recorded in mid-October. In our opinion, it was associated not with the reproduction or development of Diptera, but with the activity of this group amid high autumn temperatures. The correlation of the graphs of the temperature dynamics of September and October and the graphs of the number of Diptera indicate this. I. e., the October peaks (most likely, all autumn peaks) of the air temperature increase contributed to the increase in the activity of Diptera in all biotopes.

\section{Conclusion}

During the growing season, in total, 29 species from the Diptera family were recorded in the beer traps in five biotopes. The largest number of families was seen in birch (23 families) and pine ( 24 families) forests, the smallest number - in aspen forest (16 families). The families Muscidae, Drosophilidae, Calliphoridae had the largest numbers of captured individuals $(44.5 \%, 35.2 \%, 7.6 \%$ of the total number of individuals respectively). The largest number of Diptera was recorded in oak forest, while in four other forest biotopes (pine forest, lime forest, aspen forest and birch forest), this number was lower. The population dynamics were similar in all biotopes and had the same declines and rises. The first small significant peak in the number of Diptera in our studies occurred in the first half of summer. A slight increase in the numbers occurred in mid-June. In the second half of September, there was a gradual increase in the number and the maximum peak was recorded in mid-October, then there was a decline. The autumn increase in the number of Diptera exceeded the summer peak by several times in all five biotopes. This dynamic was typical for most families. However, species from the family Lonchaeidae peaked in July.

\section{References}

Abbes, K., Hafsi, A., Harbi, A., Mars, M., \& Chermiti, B. (2021). The black fig fly Silba adipata (Diptera: Lonchaeidae) as an emerging pest in Tunisia: Preliminary data on geographic distribution, bioecology and damage. Phytoparasitica, $49,49-59$.

Altermatt, F. (2012). Temperature-related shifts in butterfly phenology depend on the habitat. Global Change Biology, 18, 2429-2438.

Altunsoy, F., \& Kiliç, A. Y. (2012). Seasonal abundance of horse fly (Diptera: Tabanidae) in Westem Anatolia. Journal Entomological Research Society, 14(1), 95-105.

Barkalov, A. V., \& Khruleva, O. A. (2021). Hoverflies (Diptera, Syrphidae) of Wrangel Island (Chukotka Autonomous Okrug, Russia). Nature Conservation Research, 6(1), 78-87.

Bizzo, L., Gottschalk, M. S., De Toni, D. C., \& Hofmann, P. R. P. (2010). Seasonal dynamics of a drosophilid (Diptera) assemblage and its potencial as bioindicator in open environments. Theringia, 100(3), 185-191.

Blackshaw, R. P., \& Esbjerg, P. (2017). Statistical indicators for insects caught in the development trap. Journal Applied Entomology, 142, 272-276.

Bogojevic, M. S., Merdic, E., Turic, N., Jeličic, Ž., Zahirovic, Ž., Vrucina, I., \& Merdic, S. (2009). Seasonal dynamics of mosquitoes (Diptera: Culicidae) in Osijek (Croatia) for the period 1995-2004. Biologia, 64, 760-767.

Brooks, S. J., Self, A., Powney, G. D., Pearse, W. D., Penn, M., \& Paterson, G. L. J. (2017). The influence of life history traits on the phenological response of British butterflies to climate variability since the late-19th century. Ecography, 40, 1152-1165.

Carrero, D. A., Melo, D., Uribe, S., \& Wyckhuys, K. A. G. (2013). Population dynamics of Dasiops inedulis (Diptera: Lonchaeidae) and its biotic and abiotic mortality factors in Colombian sweet passionfruit orchards. Journal Pest Science, 86, 437-447.

Chen, W., Yang, L., Ren, L., Shang, Y., Wang, S., \& Guo, Y. (2019). Impact of constant versus fluctuating temperatures on the development and life history parameters of Aldrichina grahami (Diptera: Calliphoridae). Insects, 10(7), 184.

Chick, L. D., Strickler, S., Perez, A., Martin, R. A., \& Diamond, S. E. (2019). Urban heat islands advance the timing of reproduction in a social insect. Journal Thermal Biology, 80, 119-125.

Coutinho-Silva, R., Montes, M., Oliveira, G., Carvalho-Neto, F., Rohde, C., \& Garcia, A. (2017). Effects of seasonality on drosophilids (Insecta, Diptera) in the northern part of the Atlantic Forest, Brazil. Bulletin Entomological Research, 107(5), 634-644.

da Mata, R. A., Valadão, H., \& Tidon, R. (2015). Spatial and temporal dynamics of drosophilid larval assemblages associated to fruits. Revista Brasileira De Entomologia, 59(1), 50-57.

Denlinger, D. L. (1980). Seasonal and annual variation in insect abundance in the Nairobi National Park, Kenya. Biotropica, 12, 100-106.

Dufek, M. I., Oscherov, E. B., Damborsky, M. P., \& Mulieri, P. R. (2019). Calliphoridae (Diptera) in human-transformed and wild habitats: Diversity and seasonal fluctuations in the humid Chaco Ecoregion of South America. Journal Medical Entomology, 56(3), 725-736.

Dvořák, L., Dvoráková, K., Oboňa, J., \& Ruchin, A. B. (2020). Selected Diptera families caught with beer traps in the Republic of Mordovia (Russia). Nature Conservation Research, 5(4), 65-77.

Ganeva, D., \& Kalmushka, M. (2019). Seasonal abundance of horse flies (Diptera, Tabanidae) in the Chirpan Eminences, Bulgaria. Trakia Journal of Sciences, 1, 3441.

Godwin, R. M., Mayer, D. G., Brown, G. W., Leemon, D. M., \& James, P. J. (2017). Predicting nuisance fly outbreaks on cattle feedlots in subtropical Australia. Animal Production Science, 58(2), 343-349.

Hallett, C. S., Hobday, A. J., Tweedley, J. R., Thompson, P. A., McMahon, K., \& Valesini, F. J. (2018). Observed and predicted impacts of climate change on the estuaries of South-Western Australia, a Mediterranean climate region. Regional Environmental Change, 18, 1357-1373.

Handley, K., Hough-Goldstein, J., Hanks, L. M., Millar, J. G., \& D’Amico, V. (2015). Species richness and phenology of cerambycid beetles in urban forest fragments of Northern Delaware. Annals of the Entomological Society of America, 108(3), 251-262. 
Harvey, J. A., Heinen, R., Gols, R., \& Thakur, M. P. (2020). Climate change-mediated temperature extremes and insects: From outbreaks to breakdowns. Global Change Biology, 26, 6685-6701.

Höök, T. O., Foley, C. J., Collingsworth, P., Dorworth, L., Fisher, B., Hoverman, J. T., LaRue, E., Pyron, M., \& Tank, J. (2020). An assessment of the potential impacts of climate change on freshwater habitats and biota of Indiana, USA Climatic Change, 163, 1897-1916.

Johnsey, R. L., Nagel, W. P., \& Rudinsky, J. A. (1965). The Diptera Medetera aldrichii Wheeler (Dolichopodidae) and Lonchaea furnissi McAlpine (Lonchaeidae) associated with the Douglas-fir beetle in Western Oregon and Washington. Canadian Entomologist, 97(5), 521-527.

Kinjo, H., Kunimi, Y., \& Nakai, M. (2014). Effects of temperature on the reproduction and development of Drosophila suzukii (Diptera: Drosophilidae). Applied Entomology and Zoology, 49, 297-304.

Krčmar, S. (1999). Seasonal dynamics of horse flies in Eastern Croatia as a part of the Pannonian Plain (Diptera: Tabanidae). Periodicum Biologorum, 101(3), 221-228.

Krivosheina, N. P., \& Krivosheina, M. G. (2019). Saproxylic Diptera (Insecta) of the Lazovsky State Nature Reserve (Russia). Nature Conservation Research, 4(3), 78-92.

Kuussaari, M., Heliölä, J., Luoto, M., \& Pöyry, J. (2007). Determinants of loca species richness of diurnal Lepidoptera in boreal agricultural landscapes. Agriculture, Ecosystems and Environment, 122(3), 366-376.

Lysyk, T. J. (1993). Seasonal abundance of stable flies and house flies (Diptera: Muscidae) in dairies in Alberta, Canada. Joumal Medical Entomology, 30, 888-895.

MacGowan, I., Vikhrev, N. E., Krivosheina, M. G., Ruchin, A. B., \& Esin, M. N. (2021). New records of Diptera from the Republic of Mordovia, Russia. Far Eastern Entomologist, 423, 9-20.

Makaida, M. V., Pakhomov, O. Y., \& Brygadyrenko, V. V. (2021). Effect of increased ambient temperature on seasonal generation number in Lucilia sericata (Diptera, Calliphoridae). Folia Oecologica, 48(2), 191-198.

Mali, K. H., \& Zambare, S. P. (2019). Seasonal variations in life cycle of forensically important Calliphoridae fly Lucilia cuprina in Nandurbar (MS) India. International Journal of Life science and Pharma Research, A13, 19-23.

Marshall, K. E., Gotthard, K., \& Williams, C. M. (2020). Evolutionary impacts of winter climate change on insects. Current Opinion in Insect Science, 41, 54-62.

McGill, B. J., Enquist, B. J., Weiher, E., \& Westoby, M. (2006). Rebuilding community ecology from functional traits. Trends in Ecology and Evolution, 21(4), $178-185$.

Minin, A. A., Ananin, A. A., Buyvolov, Y. A., Larin, E. G., Lebedev, P. A., Polikarpova, N. V., Prokosheva, I. V., Rudenko, M. I., Sapelnikova, I. I., Fedotova, V. G., Shuyskaya, E. A., Yakovleva, M. V., \& Yantser, O. V. (2020). Recommendations to unify phenological observations in Russia. Nature Conservation Research, 5(4), 89-110.

Mullens, B. A., \& Peterson, N. G. (2005). Relationship between rainfall and stable fly (Diptera: Muscidae) abundance on California dairiesfly. Journal Medical Entomology, 42(4), 705-708

Nekrasova, L. S., Vigorov, Y. L., \& Vigorov, A. Y. (2016). Dynamics of the composition of the fauna of mosquitoes (Diptera, Culicidae) in parks of Yekaterinburg. Russian Journal of Ecology, 47(2), 186-193.

Osório, H. C., Rocha, J., Roquette, R., Guerreiro, N. M., Zé-Zé, L., Amaro, F., Silva M., \& Alves, M. J. (2020). Seasonal dynamics and spatial distribution of Aedes albopictus (Diptera: Culicidae) in a temperate region in Europe, Southern Portugal. International Journal of Environmental Research and Public Health, 17(19), 7083

Paur, J., \& Gray, D. A. (2011). Seasonal dynamics and overwintering strategy of the tachinid fly (Diptera: Tachinidae), Ormia ochracea (Bigot) in Southern California. Terrestrial Arthropod Reviews, 4, 145-156.

Pestov, S. V. (2010). Seasonal dynamics of hoverfly (Diptera, Syrphidae) activity in the taiga zone of the Komi Republic. Entomological Review, 90(6), 718-723.

Phillips, P. L., Welch, J. B., \& Kramer, M. (2004). Seasonal and spatial distributions of adult screwworms (Diptera: Calliphoridae) in the Panama Canal Area, Republic of Panama. Journal Medical Entomology, 41(1), 121-129.

Polevoi, A. V. (2021). Fungus gnats (Diptera: Bolitophilidae, Diadocidiidae, Keroplatidae, Mycetophilidae) in the Kostomuksha State Nature Reserve, Russia. Nature Conservation Research, 6(Suppl. 1), 5-16.

Poppe, J. L., Valente, V. L. S., \& Schmitz, H. J. (2013). Population dynamics of drosophilids in the Pampa biome in response to temperature. Neotropical Entomology, 42, 269-277.

Prigent, S. R., Le Gall, P., Mbunda, S. W., \& Veuille, M. (2013). Seasonal and altitudinal structure of drosophilid communities on Mt Oku (Cameroon volcanic line). Comptes Rendus Geoscience, 345, 316-326.
Rodríguez-Rodríguez, S. E., González-Hernández, H., Rodríguez-Leyva, E., Lomelí-Flores, J. R., \& Miranda-Salcedo, M. A. (2018). Species diversity and population dynamics of fruit flies (Diptera: Tephritidae) in Guerrero, Mexico. Florida Entomologist, 101, P. 113-118.

Roy, D. B., \& Sparks, T. H. (2000). Phenology of British butterflies and climate change. Global Change Biology, 6, 407-416.

Ruchin, A. B. (2021). Seasonal dynamics and spatial distribution of lepidopterans in selected locations in Mordovia, Russia. Biodiversitas, 22(5), 2569-2575.

Ruchin, A. B., \& Egorov, L. V. (2017). Overview of insect species included in the Red Data Book of Russian Federation in the Mordovia State Nature Reserve. Nature Conservation Research, 2(Suppl. 1), 2-9.

Ruchin, A. B., \& Mikhailenko, A. P. (2018). Fauna of mantids and orthopterans (Insecta: Mantodea, Orthoptera) of the Mordovia State Nature Reserve, Russia. Biodiversitas, 19(4), 1194-1206.

Ruchin, A. B., Egorov, L. V., \& Khapugin, A. A. (2021). Seasonal activity of Coleoptera attracted by fermental crown traps in forest ecosystems of Central Russia. Ecological Questions, 32(1), 37-53.

Ruchin, A. B., Egorov, L. V., \& Semishin, G. B. (2018). Fauna of click beetles (Coleoptera: Elateridae) in the interfluve of Rivers Moksha and Sura, Republic of Mordovia, Russia. Biodiversitas, 19(4), 1352-1365.

Ruchin, A. B., Egorov, L. V., Khapugin, A. A., Vikhrev, N. E., \& Esin, M. N. (2020). The use of simple crown traps for the insects collection. Nature Conservation Research, 5(1), 87-108.

Schwartz, M. D. (2003). Phenology: An integrative environmental science. Kluwe Academic Press, Dordrecht.

Semelbauer, M., Mangová, B., Barta, M., \& Kozánek, M. (2018). The factors influencing seasonal dynamics and spatial distribution of stable fly Stomoxys calcitrans (Diptera, Muscidae) within stables. Insects, 9(4), 142.

Sevidzem, S. L., \& Zinga-Koumba, C. R. (2019). Factors influencing seasonal and daily dynamics of the genus Stomoxys Geoffroy, 1762 (Diptera: Muscidae), in the Adamawa Plateau, Cameroon. International Journal of Zoology, 2019, 3636943

Shapiro, L. (1995). Parasitism of Orchelimum katydids (Orthoptera: Tettigoniidae) by Ormia lineifrons (Diptera: Tachinidae). Florida Entomologist, 78(4), 615-616.

Sinshaw, A., Abebe, G., Desquesnes, M., \& Yoni, W. (2006). Biting flies and Trypanosoma vivax infection in three highland districts bordering lake Tana, Ethiopia. Veterinary Parasitology, 142, 35-46.

Souza-Filho, M. F., Raga, A., Azevedo-Filho, J. A., Strikis, P. C., Guimarães, J. A. \& Zucchi, R. A. (2009). Diversity and seasonality of fruit flies (Diptera: Tephritidae and Lonchaeidae) and their parasitoids (Hymenoptera: Braconidae and Figitidae) in orchards of guava, loquat and peach. Brazilian Journal of Biology, $69(1), 31-40$

Stojko, T. G., \& Senkevich, V. A. (2018). Species composition and spatial structure of the zooplankton community in Lake Inorki (Mordovia State Nature Reserve, Russia). Nature Conservation Research, 3(3), 15-27.

Szyniszewska, A. M., \& Tatem, A. J. (2014). Global assessment of seasonal potentia distribution of Mediterranean fruit fly, Ceratitis capitata (Diptera: Tephritidae). PLoS One, 9(11), e111582

Tanabe, S. I., Toda, M. \& Vinokurova, A. (2001). Tree shape, forest structure and diversity of drosophilid community: Comparison between boreal and temperate birch forests. Ecological Research, 16, 369-385.

Taylor, D. B., Berkebile, D. R., \& Scholl, P. J. (2007). Stable fly population dynamics in Eastern Nebraska in relation to climatic variables. Journal Medical Entomology, 44, 765-771.

Torres, F. R., \& Madi-Ravazzi, L. (2006). Seasonal variation in natural populations of Drosophila spp. (Diptera) in two woodlands in the State of São Paulo, Brazil. Theringia, 96(4), 437-444.

Ulyshen, M. D., Soon, V., \& Hanula, J. L. (2011). Vertical distribution and seasonality of predatory wasps (Hymenoptera: Vespidae) in a temperate deciduous forest. Florida Entomologist, 94(4), 1068-1070

Uribe, M. N., Wolff, M., \& de Carvalho, C. J. B. (2010). Synanthropy and ecological aspects of Muscidae (Diptera) in a tropical dry forest ecosystem in Colombia. Revista Brasileira de Entomologia, 54(3), 462-470.

Wieher, E., Freund, D., Bunton, T., Stefanski, A., Lee, T., \& Bentivenga, S. (2011) Advances, challenges and a developing synthesis of ecological community assembly theory. Philosophical Transactions of the Royal Society B, 366(1576), 2403-2413.

Zengin, E. (2020). Occurrence of invasive species and seasonal dynamics of fruit flies (Diptera: Drosophilidae) species in Uşak province, Turkey. Revista Sociedad Entomológica Argentina, 79(1), 21-30. 